\title{
Bilateral Upper Zone Patchy Opacities on the Chest Radiography Taken for Screening in a Patient without Any Smptoms: What Is Your Diagnosis?
}

\author{
Tayfun Çalışkan ${ }^{1}$, Yasin Uyar ${ }^{1}$, Dilaver Demirel ${ }^{2}$, Oğuzhan Okutan ${ }^{1}$, Faruk Çiftçi ${ }^{1}$, \\ Ersin Demirer ${ }^{1}$, Zafer Kartaloğlu ${ }^{1}$
}

${ }^{1}$ Clinic of Chest Diseases, Gülhane Military Medical Academy Haydarpaşa Training Hospital, İstanbul ${ }^{2}$ Clinic of Pathology, Gülhane Military Medical Academy Haydarpaşa Training Hospital, İstanbul

Received Date: 16.01 .2015 Accepted Date: 28.02.2015 Available Online Date: 08.07.2015

Address for correspondence Tayfun Çalışkan

E-mail: drtcaliskan@yahoo.com

(1) \& This work is licensed under a Creative Commons Attribution-NonCommercia .0 International License.

DOI: $10.5152 /$ ejp.2015.55264

-Available online at www.eurasianjpulmonol.com

A 20-year-old male patient who worked as a salesman was referred to the Department of Chest Diseases due to opacities seen in the upper zones of both lungs on the posteroanterior chest radiography taken for screening in the tuberculosis control dispensary. The patient had no complaint, and the physical examination revealed no pathological finding. His arterial blood pressure was $110 / 70 \mathrm{mmHg}$, pulse was $88 / \mathrm{min}$, temperature was $36.7^{\circ} \mathrm{C}$, and $\mathrm{SpO}_{2}$ was $97 \%$ (oxygen-free). The results of laboratory analyses were found to be as follows: white blood cell count, $8.07 \times 10^{3} / \mu \mathrm{L}$; eosinophils, $3.46 \%$; hemoglobin, $16.6 \mathrm{~g} / \mathrm{dL}$; hematocrit, $47.8 \%$; platelet count, $274,000 / \mu \mathrm{L}$; complete urine test, normal; sedimentation, $2 \mathrm{~mm} /$ hour; C-reactive protein, $1.06 \mathrm{mg} / \mathrm{dL}$; aspartate aminotransferase, $51 \mathrm{U} / \mathrm{L}$; alanine aminotransferase, $78 \mathrm{U} / \mathrm{L}$; and urea, $25 \mathrm{mg} / \mathrm{dL}$. In arterial blood gas, the value of $\mathrm{PO}_{2}$ was 93.7 $\mathrm{mmHg}, \mathrm{PCO}_{2}$ was $33.7 \mathrm{mmHg}, \mathrm{HCO}_{3}$ was $21.1 \mathrm{mmoL} / \mathrm{L}, \mathrm{SaO}_{2}$ was $97.9 \%$, and $\mathrm{pH}$ was 7.38. The patient's posteroanterior chest radiography revealed diffuse patchy opacities in the upper and middle zones of both lungs (Figure 1). The patient had three negative sputum smear reports for acid-fast bacillus (AFB). There was a restrictive type disorder on the spirometry of the patient, and carbon monoxide diffusing capacity (DLCO) and DLCO/VA was measured as $64 \%$ and $98 \%$ respectively. High-resolution computed tomography (HRCT) of the chest revealed patchy ground-glass areas with peripheral localization,

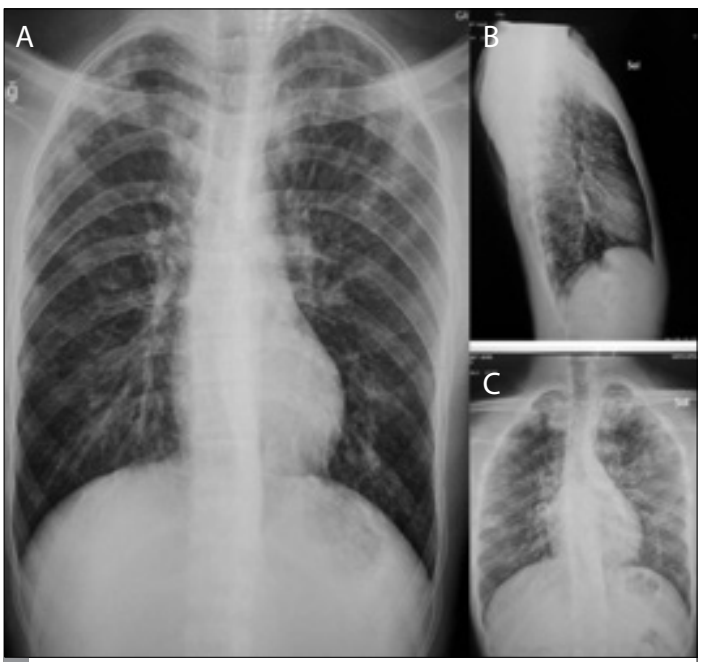

Figure 1. a-c. Diffuse patchy opacities were observed in the upper and middle zones of both lungs in the chest radiography

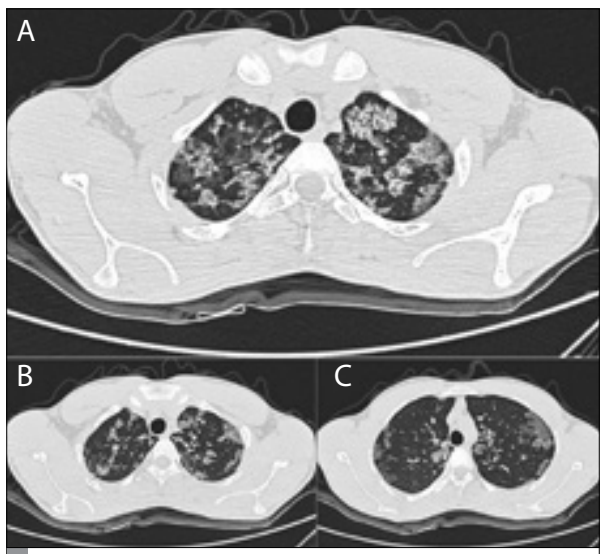

Figure 2. a-c. Patchy ground-glass areas with peripheral localization that were more apparent in the upper zones of the lungs, and interlobular septal thickness in the apical segments of the upper lobe were observed on high-resolution computed tomography of the chest 


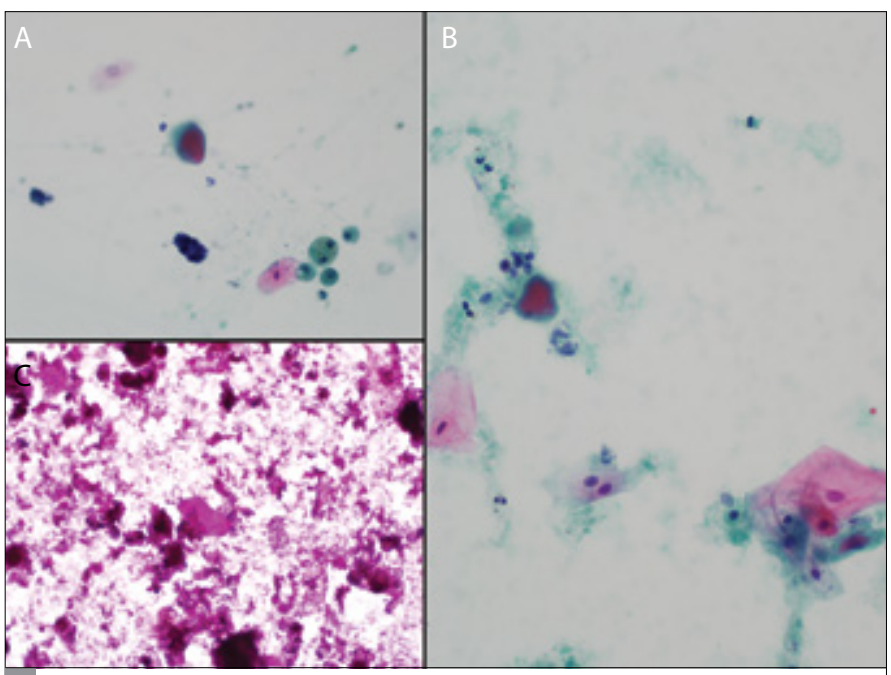

Figure 3. a-c. Acellular eosinophilic material was observed on smears, and these areas were stained as PAS positive on PAS staining which were more apparent in the upper zones of the lungs and interlobular septal thickness in the apical segments of the upper lobe (Figure 2). His anti-smooth muscle antibody (ASMA), anti-nuclear antibody (ANA), anti-microsomal antibody (AMA), and anti-HIV (ELISA) results were found to be negative. The results of bronchoscopic examination were normal, and the bronchial lavage that was taken was off-white on macroscopic evaluation. The patient was cytologically negative with regard to malignancy. Acellular, eosinophilic material was observed on the smears, and these areas were stained as PAS positive in periodic acid-Schiff stain (PAS) (Figure 3). The ARB of bronchial lavage was negative; in addition, no reproduction was observed in other cultures.

Considering clinical, laboratory, radiological, and pathological findings of the patient, what is your possible diagnosis?

a) Pulmonary tuberculosis

b) Chronic eosinophilic pneumonia

c) Pulmonary alveolar proteinosis

d) Silicosis

e) Hypersensitivity pneumonia

\section{What Is Your Diagnosis?}




\section{Pulmonary Alveolar Proteinosis}

Pulmonary alveolar proteinosis (PAP) is a rare, diffuse pulmonary disease characterized by the accumulation of PAS-positive lipoproteinaceous material (surfactant phospholipids and proteins) that is amorphous in the alveoli and terminal distal airways. The incidence of PAP is $0.2 /$ million, and its prevalence is $4-40 /$ million (1). The M/F ratio is $2 / 1$. Fifty-six percent of patients smoked. The M/F ratio in patients who do not smoke is $1 / 1$. Eighty-five percent of male patients smoked. Our case was also of a male patient who smoked.

Pulmonary alveolar proteinosis is divided into three groups: autoimmune (primary or idiopathic), secondary, and congenital (genetic) (1). Most of the primary PAP cases occur due to antibodies against granulocyte macrophage colony stimulating factor (GM-CSF). This group accounts for $90 \%$ of all PAP cases, and it is thought to occur with the inhibited function of alveolar macrophages because of antiGM-CSF antibodies (1). On the other hand, secondary PAP (8\%-10\%) occurs due to hematologic or oncologic malignancies, toxic dust inhalations (silica, aluminum, titanium), amyloidosis, infections (Nocardia, HIV, Pneumocystis jiroveci), and immunosuppression (2). In the congenital cases at the pediatric age group, mutations in the genes of surfactant protein-B (SFTPB), ABC transporter $A 3$ (ABCA3), and GMCSF receptor, which have roles in surfactant metabolism, account for secondary PAP (2). In our case, autoantibody measurement was not performed, but it was evaluated to be primary PAP after eliminating secondary causes.

The mean age during the establishment of diagnosis is 42 years, but the age of diagnosis varies between 40 days and 66 years (3). The most common symptoms among patients include dyspnea, cough, and sputum (3). Approximately one-third of patients are asymptomatic (2). The result of physical examination is generally normal but inspiratory rales, finger clubbing, and cyanosis can be observed in some patients (2). Our patient had no complaint, and his physical examination result was normal. In respiratory function tests, restrictive respiratory disorder and a low level of DLCO are detected (3). These findings were also found in our patient. For diagnosing the cases of autoimmune PAP, anti-GM-CSF is measured in the serum, and the result of $>19 \mu \mathrm{g} / \mathrm{mL}$ is a specific finding (1). In radiological evaluation, bilateral symmetric alveolar opacities (bat's wing appearance) with central/perihilar localization are observed in the middle and lower zones on chest radiography (4). Peripheral regions are generally protected. Radiological appearance resembles pulmonary edema, but there are no radiological findings such as cardiomegaly and pleurisy. Zonal predominance is usually not available radiologically, and the dominance of the lower zone is seen in $22 \%$ of cases (1). High-resolution computed tomography reveals characteristic geographical pattern (crazy-paving pattern) induced by ground-glass opacities that is superimposed with smooth reticular (septal) thickening (4). In our case, the result of HRCT was consistent with typical PAP radiology. Moreover, bronchoscopy is used for the diagnosis of the disease. Bronchoalveolar lavage (BAL) and/or transbronchial biopsy is performed through bronchoscopy. Bronchoalveolar lavage typically appears as opaque or milk-like, and alveolar macrophages containing PAS-positive material and acellular, amorphous eosinophilic PAS-positive material are observed on cytological examination (1). The diagnosis of our patient was established through BAL accompanied with radiological findings. The treatment of the disease varies depending on the severity of symptoms and gas exchange abnormalities. Monitoring is recommended for asymptomatic patients who are affected at minimal level physiologically in spite of diffuse radiological findings (5). Oxygen is given to patients with minimal symptoms and hypoxemia during exercising. For patients having severe dyspnea and hypoxemia, total lung (total lung lavage) lavage (TLL) should be performed with double-lumen endotracheal tube (6). On the other hand, for patients with final diagnosis of PAP, values of $\mathrm{PaO} 2$ lower than $65 \mathrm{mmHg}$, value of alveolar-arterial oxygen gradient higher than $40 \mathrm{mmHg}$ and value of shunt function higher than $10-12 \mathrm{mmHg}$, or severe dyspnea during rest or exercise, TPL is recommended (2). Because our patient was asymptomatic and no gas exchange abnormality was observed, we decided to follow up the patient, and TPL was not performed. The use of GM-CSF (inhaler or subcutaneous) in PAP patients is recommended for patients with progressive course of the disease despite TPL treatment (7). Lung transplantation and plasmapheresis have been performed and rituximab has been administered in selected cases, but further studies are needed on this issue. The rate of 5 -year survival is $74.7 \% \pm 8.1 \%$ in PAP patients (7). Spontaneous progression can be observed in the disease. Patients generally die of respiratory failure and uncontrolled infections (8).

Informed Consent: Written informed consent was obtained from patient who participated in this study.

Peer-review: Externally peer-reviewed.

Author contributions: Concept - T.Ç., Y.U., D.D., O.O., F.Ç., E.D., Z.K.; Design T.Ç., Y.U., D.D., O.O., F.Ç., E.D., Z.K.; Supervision - T.Ç., Y.U., D.D., O.O., F.Ç., E.D., Z.K.; Resource - T.Ç., Y.U.; Materials - T.Ç., Y.U., O.O., E.D.; Data Collection and/or Processing - T.Ç., Y.U., O.O., F.Ç., E.D., Z.K.; Analysis and/or Interpretation - T.Ç., Y.U., D.D.; Literature Search - T.Ç., Y.U., O.O., F.Ç.; Writing - T.Ç., D.D., Z.K.; Critical Reviews - O.O., F.Ç., D.D., E.D., Z.K.

Conflict of Interest: No conflict of interest was declared by the authors.

Financial Disclosure: The authors declared that this study has received no financial support.

\section{REFERENCES}

1. Borie R, Danel C, Debray MP, Taille C, Dombret MC, Aubier M, et al. Pulmonary alveolar proteinosis. Eur Respir Rev 2011; 20: 98-107. [CrossRef]

2. Khan A, Agarwal R. Pulmonary alveolar proteinosis. Respir Care 2011; 56: 1016-28. [CrossRef]

3. Xu Z, Jing J, Wang H, Xu F, Wang J. Pulmonary alveolar proteinosis in China: a systematic review of 241 cases. Respirology 2009; 14: 761-6. [CrossRef]

4. Frazier AA, Franks TJ, Cooke EO, Mohammed TL, Pugatch RD, Galvin JR. From the archives of the AFIP: pulmonary alveolar proteinosis. Radiographics 2008; 28: 883-99. [CrossRef]

5. Bhattacharyya D, Barthwal MS, Katoch CD, Rohatgi MG, Hasnain S, Rai SP, et al. Primary alveolar proteinosis - A report of two cases. Med J Armed Forces India 2013; 69: 90-3. [CrossRef]

6. Patel SM, Sekiguchi H, Reynolds JP, Krowka MJ. Pulmonary alveolar proteinosis. Can Respir J 2012; 19: 243-5.

7. Leth S, Bendstrup E, Vestergaard H, Hilberg O. Autoimmune pulmonary alveolar proteinosis: treatment options in year 2013. Respirology 2013, 18: 82-91. [CrossRef]

8. Punatar AD, Kusne S, Blair JE, Seville MT, Vikram HR. Opportunistic infections in patients with pulmonary alveolar proteinosis. J Infect 2012; 65: 173-9. [CrossRef] 